\title{
MS14-P20 | MODULAR STRUCTURES OF LAYERED URANYL MINERALS AND SYNTHETIC
}

\section{COMPOUNDS}

Nazarchuk, Evgeny (Saint-Petersburg State University, Saint-Petersburg, RUS)

There are many ways to describe topology of polyhedral complexes in the structures of uranyl compounds, one of them is a modular approach. The $\left[\left(\mathrm{UO}_{2}\right)\left(T^{6+} \mathrm{O}_{4}\right)\left(\mathrm{H}_{2} \mathrm{O}\right)_{\mathrm{n}}\right]^{0}\left(T=\mathrm{Cr}^{6+}, \mathrm{S}^{6+}, \mathrm{Se}^{6+}, \mathrm{n}=0-2\right)$ chains are the building block for a numbers of layers. Uranium compounds obtained from aqueous solutions often inherit fundamental building blocks. The layers in the structures of uranyl selenates can be obtained by the self-assembly of the $\left[\left(\mathrm{UO}_{2}\right)_{2}\left(\mathrm{SeO}_{4}\right)_{4}\left(\mathrm{H}_{2} \mathrm{O}\right)_{4}\right]^{4-}$ complexes. This approach will be generalized for all layered uranyl compounds with $\mathrm{TO}_{4}$ $\left(\mathrm{S}^{6+}, \mathrm{Se}^{6+}, \mathrm{Cr}^{6+}, \mathrm{Mo}^{6+}, \mathrm{P}^{6+}, \mathrm{As}^{6+}\right)$ tetrahedra in this contribution.

Tetramers $\left[\left(\mathrm{UO}_{2}\right)_{2}\left(\mathrm{TO}_{4}\right)_{4}(\phi)_{4}\right]^{4-}\left(\phi=\mathrm{O}, \mathrm{H}_{2} \mathrm{O}, \mathrm{F}, \mathrm{Cl}, \mathrm{OH}\right)$ in uranyl compounds are binding by free vertexes of $T \mathrm{O}_{4}$ tetrahedra to form three types of fundamental chains. Chains connected by vertex of uranium and $\mathrm{TO}_{4}$ polyhedral form layers with different $\mathrm{UO}_{2}: \mathrm{TO}_{4}=1: 2,2: 3,3: 5,4: 7,5: 8$ ratios. Thus, the layers are modular units built from separate chains.

This work was financially supported by the Russian Science Foundation through the grant 16-17-10085 and internal travel grant of SPbSU. 